\title{
History of health professional education in Nepal
}

\section{Dixit $\mathrm{H}$}

Hemang Dixit, Professor and Head, Medical Education Department, Kathmandu Medical College, Sinamangal, Kathmandu

\begin{abstract}
The introduction of Western medicine in Nepal took place during Jung Bahadur's time as Prime Minister and was slowly disseminated during the tenure of subsequent Rana Prime Ministers Bir, Chandra, Bhim and Joodha. The provision of healthcare in the country was taken as a form of charity provided to the people by the rulers. Whilst the first two government hospitals were started at Kathmandu and Birgunj, others followed as would be rulers were banished to places such as Dhankuta, Tansen or Doti. It was only after the dawn of democracy in 1950 that the Department of Health Services was established. During the past 67 years more hospitals and academic centres for teaching health sciences have come up in different parts of Nepal. Strides have made in the delivery of health care and health sciences education. Much more needs still to be done.
\end{abstract}

Key words: Academies, Health services education, Medical education

\section{BACKGROUND}

In: n former times, the Nepalis believed and prayed to various deities for protection. There existed in Nepal a traditional system of healthcare in the country. There were and still exist to this day various traditional practitioners such a Dhamis, Jhakris and Jharphuks. Anshu Verma (605-641) had in 620 AD some Arogyashalas or healing houses built in the country'. There were traditional healers being trained in apprentice fashion. Later rulers - Pratap Malla (1641-1671) and both Ranjit Malla and Jayaprakash Malls in 1740 allowed missionaries to introduce Allopathic medicine into $\mathrm{Nepal}^{2}$. The method of dealing with problems of the teeth then was to nail a coin into the Bangemuda in town!

The Western system of medicine as we know it today started at Oxford in England in 1540. It was customary at that time to study anatomy for five years and then learn about clinical aspects, diseases and therapeutics during the sixth year. Apprenticeship to surgeons or physicians was the next step prior to starting out in practice on one's own. It was after the British and others invaded the colonies and ruled the people there that they had to make facilities to not only look after themselves but also others in these lands. Of course they had brought along some personnel but these were not enough. After

Address for correspondence

\section{Hemang Dixit}

Professor and Head, Medical Education Department

Kathmandu Medical College, Sinamangal, Kathmandu, Nepal

E-mail: h2dixit@gmail.com landing in India, the colonisers started medical schools - the British at Calcutta and Madras in 1835 and the Portuguese at Goa in 1842. The courses started by the British were initially Licentiates of the health assistant type which were later upgraded to doctor level.

Jung Bahadur visited both England and France in 1850 and was impressed by what he saw in these lands. He also went to the Royal College of Surgeons in Edinburgh and brought back many ideas. The English 'Common Law' and the 'Code Napoleon' gave some of the basis for the Muluki Ain that he had scribes to workout and got enacted for Nepal. There were some provisions concerning Medical Practice in it. Though updated during King Mahendra's time it has now been updated during Republican times. This new version again become legal from $1^{\text {st }}$ Bhadra 2074 (17 August 2018).

The introduction of the Western form of medical education was accepted round about 1928 when a Dr. Krishna Raj Mukerjee was appointed as the head of an institution - called Nepal Medical College ${ }^{3}$. This same institution was possibly renamed as the Civil Medical School in 1934 to start the training of compounders and dressers in Nepal.

\section{TRAINING OF MIDWIVES}

The training of midwives for Nepal started with the sending of four Nepali girls to be trained in midwifery to Allahabad in 1928 for the eighteen months training and on return were posted in Bir Hospital. The training 
of a cadre, Auxiliary Nurse Midwives (ANM) to provide midwifery was started at first at Hetauda in 1958. After the production of three batches this institution was transferred in 1963 to Bharatpur by the Ministry of Health (MoH). After the establishment of the Institute of Medicine(loM) in 1972 the certificate level courses were conducted at Maharajgunj and Patan. Later the five ANM schools at Bharatpur, Biratnagar (1981), Pokhara (1984), Birgunj (1986) and Nepalgunj (1987) were upgraded to conduct nursing courses. The Government of Nepal has felt the need of midwives again and has taken new steps for that.

\section{START OF HRH TRAINING}

Health personnel education started in Nepal with the formation of the Nepal Rajakiya Ayurved Vidyalaya in $1933 / 34$ for the training of baidyas and other categories of ayurvedic personnel ${ }^{1}$. The school produced the Ayurvedic manpower required for the country till this training institution was incorporated into the Institute of Medicine in 1972.

Training for compounders and dressers also started in 1934 in the newly opened Civil Medical School. Though doctors from Bengal in India were taken into the medical service in Nepal, it was the compounders and dressers trained within the country by this institution that effectively ran the hospitals and smaller units under the supervision of doctors ${ }^{4}$.

A Health Assistant level of training was started in 1956 by the Ministry of Health at Bir Hospital. A total number of 65 persons who enrolled and completed this course were told that they would later be given further opportunities to do upgrading courses and qualify as doctors. These were among the basic and middle levels health workers, the training of whom was later transferred to the loM when it was created in 1972.

Though the idea of starting a medical school in Nepal had first been suggested in 1963 it was temporarily shelved in preference to starting courses for various grades of middle level health workers. Then in mid July 1972 Tribhuvan University (TU) was reconstituted under the New Education System Plan (NESP) and the Institute of Medicine (IoM) established as an institute. The IoM initially continued the production of basic and middle level health workers such as AHWs, ANMs, CMAs, health assistants, laboratory, X-ray and pharmacy technicians plus also ayurvedic baidyas and nurses ${ }^{2}$. A middle level Health and Sanitation course was also conducted for a few years.
The first batch of 22 students, 12 from the health assistant stream and 2 each from the other five groups were admitted in 1978. Basic Sciences were taught at Maharajgunj and clinical at Bir, Prasuti Griha and Kanti Children's Hospital. Though the course was of 4 and half years duration the first batch completed their studies only in 1984. To carry out its academic activities, new facilities for loM were established with aid of the Japanese government and the hospital at Maharajgunj started operating from 1984 too.

At the time that the first medical college was started, the clarion call of the world was that there should be 'Health For All by 2000 ' or 'HFA 2000'. There was also the feeling at that time that the health services could not be provided by the doctor alone but rather by a 'Health Team' headed by a doctor. This was not only a slogan but a reality in Nepal where the units providing health care to the people were not only scanty and stretched out, but also ill-equipped. The practice to meet with the community demands was to post a doctor there but the reality was that the individual could hardly function without the support of a health team.

\section{FURTHER TRENDS OF MEDICAL EDUCATION}

Following in loM's footsteps, an institution started by the government with the help of the Government of India, was the BP Koirala Institute of Health Sciences (BPKIHS) at Dharan in 1993. This was a deemed university and as a result conducted, besides the medical course, a host of other health related programmes.

\section{POST-GRADUATION IN MEDICAL EDUCATION}

The loM started the first post graduate course of MD GP in 1982 and then in other areas. As from 1994 a Post Graduate Committee was formed comprising of faculty and consultants of loM and Bir Hospital and a number of PG courses started too. In 2002 the government set up the National Academy of Health Sciences which started its own programs of post graduate courses in medicine and surgery at Bir and the Valley Group of Hospitals. Another Deemed University, the Patan Academy of Health Sciences came into being as from 2010 and has been conducting the MBBS and nursing courses. A Karnali Academy of Health Sciences (KAHS) at Jumla though officially established in 2007 started functioning only in 2011 and is presently conducting courses for middle level workers. Political commitment which has been made is that there will be an Academy of Health Sciences (Deemed University) in each of the seven provinces as envisioned by the newly promulgated constitution of Nepal. The government also announced 
that it will set up an Academy of Health Sciences at Pokhara in the Western Region of the country. Currently a medical college is in the process of being set up in the Gaeta VDC of Kailali district of the Far West region. Another announcement made is for an institute of health sciences at Gorahi in Dang. People in Lumbini are demanding one there too.

A four member High Level Medical Education Commission was formed in June 2017 under Mr. Gauri Bahadur Karki, including Dr. Upendra Devkota and Mr. Surya P Gautam. Though initially formed for three months the period was extended and a report was finally submitted in six months.

Other areas: During the period $1955-1972$ there was stress on the production of health assistants and basic level workers such as AHWs and CMAs to provide health care to the people. Training responsibility for these grades was initially under loM. Now the middle and basic level of health care workers are trained in Institutes under the Centre for Technical Education and Vocational Training (CTEVT) which had been established as early as 1989. After the loM discontinued the auxiliary courses, because of policy, the responsibility of continuity was taken by the CTEVT in 1992. The training of the various grades of health workers in the areas of Laboratory, X-ray, Pharmacy Technicians, and Ayurved were thus not neglected. Though education in these sectors was first started by loM under TU, various colleges being affiliated to other universities and also to CTEVT are now conducting such programmes.

\section{DENTAL EDUCATION}

After the starting of the MBBS in 1978, some attempts had been made as early as 1993, when DY Patil tried to start a dental college at Nepalgunj, but without success. BPKIHS, a Deemed University started a dental college at Dharan and was the first to start the BDS program in Aug. 1999. Subsequently in Nov. 1999 the Peoples Dental College in the private sector started the training of dental surgeons with the Bachelor of Dental Surgery under $\mathrm{TU}^{5}$. Currently there are thirteen colleges offering dental courses. Two of these are those of the BPKIHS at Dharan and KU at Dhulikhel, whilst the other eleven are five affiliated to $\mathrm{KU}$ and six to TU.

\section{POST-GRADUATION IN DENTAL EDUCATION}

BDS dental graduates after complete a bridge course were allowed by BPKIHS at Dharan to do Post Graduation in Basic Sciences and Forensic Medicine from 2003 to 2008 because of the extreme shortage of faculty in the concerned subjects. Subsequently in $2011 \mathrm{KU}$ too started this practice on allowing BDS graduates to do MS/MD in basic science subjects only. PG in Dental Education was first started by Kathmandu University in 2003 but the course was conducted at Manipal and Mangalore in India with the co-operation of the Manipal Academy of Health Sciences. PG education in Nepal started only in 2008. Presently there are six institutions offering PG-Masters in Dental Surgery (MDS) as constituent programs or in affiliation with BPKIHS, TU, NAMS or KU.

\section{NURSING EDUCATION}

The Mahaboudha Nursing Campus was shifted to IoM in 1986 as Maharajgunj Nursing Campus. In 1978 the IoM started higher grades of nursing studies i.e. BN, labelled 'Diploma' at the time that MBBS was started. The nineties also saw the starting of the BN at Lalitpur also. Though initially of general adult nursing these were later expanded to cover specific areas such as Community Medicine, Adult Medical, Surgical and Paediatric Nursing.

In 1992 the auxiliary courses in nursing were transferred to CTEVT. From 1993 entry to certificate level courses had been made to be $10+2$.

Later in the 2nd millennium, the BSc Nursing courses of study were started under TU, KU and Purvanchal University (PU). Then in 2010, KU too started a Post Basic course, for those with a science background who wanted a degree. This Bachelor in Nursing Science (BNS) is comparable to the $\mathrm{BN}$ degree given by TU.

\section{MIDWIFERY}

As stated earlier midwifery education had been started very early with the training of Assistant Nurse Midwives in at Hetauda and later transferred to Bharatpur in 1963. Whilst the current training of this grade is being done by CTEVT the government with the aid of academic institutions has requested TU, KU and BPKIHS to start Bachelor Level courses in Midwifery.

\section{AYURVED EDUCATION}

Following the implementation of the NESP in 1972 the training of ayurvedic practitioners was transferred to Tribhuvan University (TU). loM then started the degree course of Bachelor of Ayurvedic Medicine \& Surgery (BAMS). In 2006 the Ayurved Campus of TU was shifted to Kirtipur and conducted the BAMS course there. Sometime later the Sanskrit University started the training of baidyas and BAMS at Dang also, but now does the degree course only. As from 2011 the Ayurved Campus has started the MD (Ayurved) also. 


\section{PHARMACY EDUCATION}

Though the loM started the Proficiency Certificate Level $(P C L)$ training in early seventies, the Bachelor grade of personnel were trained outside, mostly in India. It was KU which started the Bachelor degree course (B.Pharmacy) in the 1990s and subsequently the Masters (M. Pharmacy) in $2000^{6}$. TU also started the Bachelor course at loM in 2000.

There are 25 colleges under CTEVT which conduct the 3 years Diploma course with the idea that the 1000 personnel produced per year will find employment in the retail pharmacy sector ${ }^{3}$.

Twenty colleges under four universities, i.e. TU, KU, Pokhara and Purbanchal Universities each run the Bachelor program. In addition TU has 7 affiliates, Pokhara University has 3 affiliates and Purbanchal has 7 affiliates running the Bachelor degree course. A total of about 560 graduates are produced every year. Most of the products of the Degree program are employed in the pharmaceutical industrial sector producing drugs for both human and veterinary consumption.

\section{PHYSIOTHERAPY EDUCATION}

Physiotherapy practise in Nepal was started in 1972 by army personnel trained in India who then started working in the Military Hospital in Nepal' ${ }^{7}$. An attempt was made to start a Certificate level course in physiotherapy in the country as far back as 1983 without success. Later the Dhulikhel Medical Institute, under KU ran such a course from 2003-2008. Subsequently KU upgraded this to a Bachelor Level course in 2010.

\section{NUTRITION EDUCATION}

Dieticians have a role to play in the care of the ill. Though dieticians or experts in nutrition are required for the delivery of health care to the people, the reality was that prospective students had to go out of the country, mainly to India, to study in this area. In the government sector the Maharajgunj Campus under the Institute of Medicine has started a two year course in Nutrition under the heading of MPH N, with an intake of five candidates in 2015. Two batches have finished the course. In the private sector the College of Applied Food \& Dairy Technology (CAFODAT) offers a two years course in Masters in Nutrition \& Dietetics.

\section{POST-GRADUATE MEDICAL EDUCATION}

As stated already the training of post graduate general practitioners or 'generalists' as they came to be known was in 1982. Subsequently in 1994, three programmes for PG studies were started in the Valley Group of Hospitals and the degree was awarded by TU.

To further the development of post graduate studies in various specialities, the National Academy of Medical Sciences (NAMS) was started by the government 2002 as an autonomous body. In 2004 it was given the status of an autonomous post graduate institution based at the Bir Hospital.

By this time both the TU and Kathmandu University (KU) expanded their PG programmes. Subsequently both universities also started various PG programmes in the various affiliated colleges.

\section{PRESENT STATE AND FUTURE PROBLEMS}

The current situation regarding teaching students in the government and private sector institutions running health professional courses is as follows:

\section{Government Sector:}

Universities: Tribhuvan University - loM has seven medical colleges plus six dental affiliated colleges. Also Public Health, Nursing and Laboratory, X-Ray, Pharmacy and Ayurved programmes. Other universities e.g. Pokhara \& Purbanchal run programmes in public health.

Deemed Universities: BPKIHS runs many programmes. PAHS currently has the MBBS and the nursing programmes which it inherited from loM. It has recently started some PG programmes - MD GP. KAHS presently runs middle and basic level courses.

Basic and Middle level courses are also conducted by the CTEVT in both government and private institutions in different parts of the country.

\section{Private Sector:}

University: Kathmandu University is a university in the Non Governmental sector established by private individuals on a non-profit basis as a social cause ${ }^{8}$. The PM of Nepal is the Chancellor with Education Minister, representatives of National Planning Commission and a number of ministerial secretaries being members of the Senate. It first started the MBBS and BDS courses at affiliated colleges in 1994 and 1997. Its own courses in medicine and dental surgery also began in 2001 and 2011 respectively. Presently, besides these two programs at Dhulikhel, it has affiliated 9 medical and 5 dental colleges located around the country. Together with these the Bachelor degree in Nursing are run at four of its affiliated colleges. Pharmacy and Physiotherapy degree courses are also done at its central campus in Dhulikhel. 
With the setting up of different programmes and colleges in different parts of the country, the government came up with the concept of Private and Public Mix. It is as a result of this that health services are being provided in more outlying parts of the country. This is very essential as the present constitution of Nepal has made health rights a basic right of the people. Though started initially in some of the 77 districts of Nepal, commitment has been made towards providing Health Insurance to all the people of this land.

Voices for setting up a Health Sciences / Medical University had been in the air in Nepal some years ago. Comparison had been made to some provinces in India e.g. Tamil Nadu and Haryana which already have a University functioning in these provinces. Other provinces are expected to do so in the future.

\section{REFORM OF MEDICAL / HEALTH SCIENCES EDUCATION}

There has been a thought going on for a long time that the medical fraternity should be more humane towards the patients whom they serve. The feeling is that the medical students should have some training in the humanities together with instruction in communicating skills as communication is something which doctors do all their lives.

The clamour for changes in medical education has been going on since the time that the IoM was established when the course was started in 1978 with Community orientation, integrated teaching and some problem based learning. These concepts were also followed when BPKIHS started functioning at Dharan. The MBBS course at KU was as per the SPICES model or in elaboration -Student centred, Problem based Integrated, Community oriented, with Elective choice and System based. There had been suggestions in the past to form an Apex body that would oversee, admissions and final examinations at both Undergraduate and Postgraduate level so that the standards of the graduates and post-graduates produced in Nepal are uniform. The fact is that over the course of the last 39 years, since the starting of MBBS, Nepal has achieved some success in the medical education field, but not enough.

After the student unrest of 1979 (2036 BS) at the time that Prof. Surya Bahadur Shakya was Vice Chancellor of TU, there was talk of forming a Technical University which would include an Institute of Medicine or an Institute of Health Sciences. Now with vast complex of medical education in the country, the Kedar Bhakta
Mathema Commission was formed in Jan. 2015 and submitted its report in June 2015. After this a subsequent commission prepared a draft of an act to implement the recommendations of this commission. This act had difficulty in being endorsed by parliament. Following this, yet another committee under the chairmanship of Dr. Shiba K Rai made suggestions for the regulation of fees charged by private medical colleges. A further set of recommendations by a committee headed by Dr. Bhagwan Koirala was then made and submitted its report.

The medical colleges in different parts of the country are in a state of tension, not knowing what is in store for the future. Nepali students who could be admitted in institutions within the country are going out, spending foreign exchange for their educational needs, when they could be catered for in Nepal. But there is something in the air. Nepal Government on 28th Feb. 2017 has made many changes in the six health related councils that regulate the standards and various aspects of functioning in health related fields. On 1st March the following day a number of VC's of Deemed Universities were also appointed. Was this a signal of impending changes in the future or just tactics to delay matters? One can only hope and wait. In the meantime the country has witnessed the thirteen hunger strikes that Dr. Govinda $\mathrm{KC}$ has undertaken during the course of the last few years. Besides the regulation of medical education in this country, he has been advocating for the autonomy for loM, a state promised but never implemented by TU.

After much discussion and 'political shuttle cocking' in the House, the National Medical Education Ordinance as per Article 114 of the Constitution had been endorsed by PM Sher Bahadur Deuba's cabinet and forwarded to the President Bidhya Devi Bhandari on 23rd October for authentication as Parliament had been dissolved for the election. This was done on 10th November 2017. This however is not the end of the story for it has to be endorsed by both houses of the new parliament within its first sixty days of its opening.

\section{ACKNOWLEDGEMENT}

I would like to express my gratitude to Prof. Dr. Ramesh K Adhikari, Prof. Dr. Rabindra Man Shrestha, Mr. Eurek Ranjit and Mr. Sanjaya Mani Dixit for helping me and giving their kind suggestions for improving the same. This article is based on the AHPEN Oration that I gave on the occasion of the First Conference of the Association of Health Professional Educationists of Nepal held at Kathmandu on 3rd \& 4th December 2017. 


\section{REFERENCES}

1. Marasini B. Health and hospitals development in Nepal: past and present. J Nepal Med Assoc. 2003;42:306-11.

2. Dixit H. Nepal's Quest for Health. Kathmandu: Education Publishing House. 2014; 4th edition.

3. Shrestha IB. Health Personnel Training in Nepal. J Inst Med. 1979;1(2),155-72.

4. Dixit H. Bir Hospital of Yore and Now. JKMC. 2014;3(4):177-80.
5. Shrestha RM. Evolution \& Present Status of Dental Education in Nepal. AHPEN Souvenir.2017:42-6.

6. Ranjit E. Beginnings, Development \& Status of Pharmacy Education in Nepal. AHPEN Souvenir. 2017:47-50.

7. Shijagurumayum R.DoweknowaboutPhysiotherapy in Nepal?. AHPEN Souvenir.2017.60-2.

8. Adhikari S. Chikitsa shikshyama phadko. Lalitpur: Shikshak Maashik Gyan- Bigyan Shaikshik Sahakari Sanstha Limited. 2013; 1st edition. 